\title{
Frequency of urinary tract infections among pregnant women receiving antenatal care in a tertiary care centre: hospital based cross-sectional study
}

\author{
Kumari Sadhvi, Varsha Kose*
}

Department of Obstetrics and Gynaecology, NKP Salve Institute of Medical Sciences and Research Centre and Lata Mangeshkar Hospital, Hingna Road, Nagpur, Maharashtra, India

Received: 08 October 2020

Revised: 04 December 2020

Accepted: 05 December 2020

\section{*Correspondence:}

Dr. Varsha Kose,

E-mail: varshadkose@gmail.com

Copyright: ( $)$ the author(s), publisher and licensee Medip Academy. This is an open-access article distributed under the terms of the Creative Commons Attribution Non-Commercial License, which permits unrestricted non-commercial use, distribution, and reproduction in any medium, provided the original work is properly cited.

\begin{abstract}
Background: Urinary tract infections (UTI) are one of the most frequent human bacterial infections, causing substantial morbidity and mortality, with nearly 150 million cases globally per year. The prevalence of UTI (including both asymptomatic bacteriuria and symptomatic infection) in pregnant women in India is reported to range from $3 \%$ to $24 \%$. This infection must be adequately diagnosed and efficient treatment must be initiated to prevent maternal and perinatal morbidity.

Methods: This was a hospital based cross sectional study. 625 ante natal women recruited during first visit attending antenatal care outpatient department (ANC OPD). We tested their clean catch mid-stream urine sample for routine, microscopic and culture sensitivity test.

Results: Out of 625 antenatal women frequency of urinary tract infection was $16.2 \%$. $17 \%$ women were symptomatic having one or more symptoms indicative of urinary tract infection and $83 \%$ women were asymptomatic. Among symptomatic women, $92.5 \%$ women showed culture positivity for one or more bacteria whereas in asymptomatic women, culture was positive in $10.8 \%$. E. coli followed by Klebsiella were the most common isolate identified in both symptomatic and asymptomatic women. On antibiotic sensitivity testing, we found good overall sensitivity of bacteria to commonly used antibiotics such as nitrofurantoin, and norfloxacin but resistant to ampicillin was observed in all women. UTI adversely affects the mother like pyelonephritis, preterm labour and preterm baby and its complications. Conclusions: It is important to identify presence of UTI during pregnancy by doing urine routine and culture sensitivity test in all antenatal women and administration of appropriate antibiotic to affected women so as to reduce the morbidity both in mother and baby.
\end{abstract}

Keywords: Antenatal women, Asymptomatic bacteriuria, Urinary tract infection

\section{INTRODUCTION}

Urinary tract infections (UTI) are one of the most frequent human bacterial infections, causing substantial morbidity and mortality, with nearly 150 million cases globally per year. ${ }^{1}$ The lifetime incidence of UTI in women is $50-60 \% .^{2}$ The chance of developing UTI in females is 30 times more than men due to anatomy of the female urinary tract. UTI in pregnant women continue to pose a clinical problem and challenge for obstetricians and physicians. The prevalence of UTI (including both asymptomatic bacteriuria and symptomatic infection) in pregnant women in India is reported to range from $3 \%$ to $24 \%$. $^{3}$

The uropathogens that cause UTIs during pregnancy are the same as those found in nonpregnant patients. Escherichia coli accounts for 80 to $90 \%$ of infections. 
Other gram-negative organisms such as Proteus mirabilis and Klebsiella pneumoniae are also common. Grampositive organisms such as group B Streptococcus and Staphylococcus saprophyticus are less common causes of UTI. ${ }^{4}$ In a study from South India, Manjula et al found E. coli as the most frequently isolated organism (56.79\%), followed by Klebsiella (19.9\%), Pseudomonas (6.3\%), and Proteus (5.8\%). ${ }^{5}$ WHO and NICE guidelines state that mid-stream urine culture is the recommended method for diagnosing asymptomatic bacteriuria (ASB) in pregnancy. 6,7

Choosing the right antimicrobial agent in right dose and duration is an essential part of managing pregnant patients with UTI. The main evidence for treating asymptomatic bacteriuria in pregnancy to prevent adverse maternal and fetal outcomes resulted from a Cochrane Review in 2000 which showed that when antimicrobial treatment was compared to placebo or no treatment it was effective in clearing asymptomatic bacteriuria [risk ratio (RR) 0.25], reducing risk of pyelonephritis (RR 0.23) and reducing the incidence of low birth weight babies (RR $0.66)^{8}$

Without treatment, up to 20 to $30 \%$ of pregnant women with asymptomatic bacteriuria will develop a symptomatic urinary tract infection (cystitis and pyelonephritis) during pregnancy. Maternal complications of UTI in pregnancy include premature delivery, pre-eclampsia, sepsis and chronic renal disease whereas fetal complications are pre-mature or low-birthweight infants leading to increase neonatal mortality and morbidity. ${ }^{9}$

Therefore we undertook this study (1) to determine the frequency of urinary tract infections among symptomatic and asymptomatic pregnant women and (2) to identify isolated bacterial uropathogen and their drug sensitivity pattern to selected antimicrobial agents.

\section{METHODS}

This cross sectional study was conducted in department of Obstetrics and Gynaecology NKP Salve institute of medical sciences and Lata Mangeshkar hospital Hingna Road, Nagpur A Rural Based Tertiary Care Centre from October 2017 to September 2019 (2 year). 625 antenatal women recruited, after taking approval from Institutional Ethics Committee.

Sample size was determined using the following formula.

$2 \mathrm{~N}=1.962 \times$ Prevalence (1-Prevalence)/ L.

L: Allowable error (error max) based on the reported prevalence of $24 \%$ in previous studies from India. ${ }^{10}$

We used a convenient sampling technique.

\section{Inclusion criteria}

All pregnant women having symptomatic or asymptomatic UTI above 18 years of age came to us during their first antenatal visit and willing to participate in the study were included.

\section{Exclusion criteria}

Women who had taken antibiotics for any illness within 7 days or presently taking any antibiotics and those who are not willing to participate in this study were excluded.

Written and informed consent was taken from the patients who were ready to participate in the study and who fulfilled inclusion and exclusion criteria. Detailed history was taken including patient's age, address, education, occupation, income was noted. Socioeconomic status was determined by Modified Kuppuswamy Scale, menstrual history, obstetric history, and duration of pregnancy was noted. Specific questions related to symptoms and signs of UTI such as burning micturition, dysuria, fever, flank pain, suprapubic pain, urgency, frequency, haematuria, nocturia were asked. Each participant was carefully asked for relevant history of UTI prior to pregnancy, UTI in previous pregnancy any other history that relates to this study was obtained. Detailed history regarding present ailments and use of medications or antibiotics in last 7 days was obtained. Family history, past history, personal history and relevant history was noted.

All women were subjected to clinical examination, general and systemic examination. Apart from other normal routine antenatal investigations, mid-stream urine routine test, urine culture and sensitivity was done and results were noted. Patients were managed as per hospital protocol. Data was documented in case record form and entered in excel sheet. Confidentiality was maintained.

\section{Collection of urine samples}

Women were informed to clean their hands with soap and water and then clean the vulva and perineum with sterile cotton swab soaked in normal saline to reduce the risk of contamination. Clean catch mid-stream urine sample was collected using sterile, wide- mouthed glass bottles with screw cap top. Urine specimen was processed in the laboratory within half an hour of collection. The specimen that could not be processed within two hours was kept in refrigerator at $4^{\circ} \mathrm{C}$ until it was processed. Urine routine microscopy examination was done in department of the pathology and urine culture sensitivity done in the department of microbiology. Urine culture of microorganisms in urine was done by cysteine lactose electrolyte deficient (CLED) medium/MacConkey agar and blood agar using standard loop by Semi-quantitative method and culture sensitivity test was done by disc diffusion method/by calibrated loop method. The plates were read after $24 \mathrm{~h}$ of aerobic incubation at $37^{\circ} \mathrm{C}$. They were incubated for another 24 hours before a negative 
report was issued. A sample with single organism obtained in counts $>10$ colony forming units $(\mathrm{cfu} / \mathrm{ml})$ was taken as positive for bacteriuria. If any pathogen was identified in urine of asymptomatic women, repeat midstream urine sample was taken and sent for repeat culture and sensitivity test. Sensitivity testing was done using drugs safe in pregnancy namely amoxycillin, ampicillin, cephalexin, cefuroxime, cefotaxime, nitrofurantoin, levofloxacin, imipenem.

\section{Operational definitions ${ }^{3}$}

\section{Urinary tract infection (UTI)}

UTI was defined by isolation of one or more pathogen on urine culture of morning mid-stream sample in symptomatic and asymptomatic cases.

\section{Asymptomatic bacteriuria $(A B U)$}

ABU defined as true bacteriuria (more than 100,000 colony forming units $(\mathrm{CFU}) / \mathrm{ml}$ ) in the absence of specific symptoms of acute urinary tract infection.

\section{Symptomatic bacteriuria}

Patient having symptoms related to urinary infection and the colony count in a single culture was 103 or more were considered as symptomatic UTI.

\section{Acute cystitis}

It was defined in presence of significant bacteriuria with associated bladder mucosal invasion, and is distinguished from asymptomatic bacteriuria by the presence of symptoms such as dysuria, urgency, frequency, nocturia, haematuria and suprapubic discomfort in afebrile women with no evidence of systemic illness.

\section{Pyelonephritis}

The identification of at least 100,000 bacteria/ml of a single uropathogen in a midstream specimen of urine culture with associated inflammation of the renal parenchyma, calices and pelvis in the presence of systemic illness. Symptoms include flank or renal angle pain, pyrexia, rigor, chills, nausea and vomiting.

\section{RESULTS}

Out of 625 antenatal women attending obstetrics and gynecology OPD majority of women belonged to age group $21 \mathrm{yr}$. to $30 \mathrm{yr}$. mean age was 25.3 year. According to Kuppuswamy scale $29 \%$ of the women belonged to be in upper lower class, $26.5 \%$ lower class $21.8 \%$ lower middle class and $22.6 \%$ in upper middle class.

Mean gestational age in our study participant was 25.3 weeks. $45.8 \%$ were in second trimester, $37.9 \%$ were in first trimester, $16.3 \%$ were in third trimester. $65.6 \%$ women in our study were multigravida whereas $34.4 \%$ women were primigravida (Table 1).

Table 1: Distribution of participants as symptomatic and asymptomatic.

\begin{tabular}{|lll|}
\hline Patient groups & Frequency & Percentage \\
\hline Symptomatic & 106 & 17.0 \\
\hline Asymptomatic & 519 & 83.0 \\
\hline Total & 625 & 100.0 \\
\hline
\end{tabular}

Table 1 shows the distribution of participants according to presence and absence of symptoms of UTI. Out of total 625 participants, 106 women (17\%) were having symptoms of UTI whereas $519(83 \%)$ women were asymptomatic (Table 2).

Table 2: Distribution of urinary symptoms in symptomatic women $(n=106)$.

\begin{tabular}{|lll|}
\hline Symptoms and signs & Frequency & Percentage \\
\hline Dysuria & 79 & 74.5 \\
\hline Burning micturition & 58 & 54.7 \\
\hline Pain in abdomen & 43 & 40.6 \\
\hline Frequent urination & 38 & 35.8 \\
\hline Urgency & 35 & 33.0 \\
\hline Bach ache & 35 & 33.0 \\
\hline Fever & 29 & 27.4 \\
\hline Flank pain & 27 & 25.5 \\
\hline Suprapubic pain & 15 & 14.2 \\
\hline
\end{tabular}

Table 2 shows the distribution of urinary symptoms in symptomatic women Most commonly reported symptom was dysuria $(74.5 \%)$ followed by burning micturition (54.7\%), pain in abdomen (40.6\%), frequent urination $(35.8 \%)$, urgency $(33 \%)$, back ache $(33 \%)$, fever $(27.4 \%)$, flank pain $(25.5 \%)$ and suprapubic pain (14.2\%). As many women had more than one symptom, there was overlap of symptoms (Table 3 ).

Table 3: Distribution of patients according to presence of UTI.

\begin{tabular}{|lll|l|}
\hline Patient group & UTI & $\begin{array}{l}\text { Total } \\
\text { women }\end{array}$ \\
\cline { 2 - 4 } Symptomatic & $98(92.45 \%)$ & $8(7.5 \%)$ & $106(17 \%)$ \\
\hline Asymptomatic & $56(10.7 \%)$ & $463(89.21 \%)$ & $519(83 \%)$ \\
\hline Total & $154(24.6 \%)$ & $471(75.36 \%)$ & $625(100 \%)$ \\
\hline
\end{tabular}

Table 3 shows distribution of women according to presence or absence of positive urine culture report in the participants. Out of total 625 women, 154 women had UTI suggesting prevalence of UTI in our study to be $24.6 \%$. From 106 symptomatic women, $92.45 \%$ of them had UTI. Out of 519 women who did not have symptoms, 56 i.e. only $10.7 \%$ women had UTI. The difference in proportion of patients with UTI in two groups of women 
was significant as suggested by $\mathrm{p}$ value $<0.0001$. This shows that if symptoms of UTI are present, there are high chances of UTI but small number of patients (10.7\%) can have UTI without urinary symptoms (Table 4).

Table 4 shows the distribution of type of organism in two groups. Among symptomatic and asymptomatic women with UTI, most commonly isolated organism was E. coli (35.7\% and $32.1 \%)$. Other organisms in two groups of women included Klebsiella pneumoniae (14.3\% and $17.9 \%)$, Proteus spp. (9.2\% and 10.7\%), P. aeruginosa (9.2\% and $3.6 \%), S$. aureus (17.3\% and $14.3 \%)$, S. Saprophyticus $(9.2 \%$ and $10.7 \%)$ and Enterococcus spp. (5.1\% and $10.7 \%$ ) (Table 5 and 6).

Table 4: Distribution of type of organism in two groups.

\begin{tabular}{|lll|}
\hline Type of organism & Symptomatic women with UTI n=98 (\%) & Asymptomatic women with UTI n=56 (\%) \\
\hline E. coli & $35(35.7)$ & $18(32.1)$ \\
\hline Klebsiella pnemoniae & $14(14.3)$ & $10(17.9)$ \\
\hline Proteus spp. & $9(9.2)$ & $6(10.7)$ \\
\hline Pseudomonas aeruginosa & $9(9.2)$ & $2(3.6)$ \\
\hline S. aureus & $17(17.3)$ & $8(14.3)$ \\
\hline S. saprophyticus & $9(9.2)$ & $6(10.7)$ \\
\hline Enterococcus spp. & $5(5.1)$ & $6(10.7)$ \\
\hline Total 154 & $98(100.0)$ & $56(100.0)$ \\
\hline
\end{tabular}

Table 5: Culture sensitivity of bacteria in symptomatic patients ( $n=98)$.

\begin{tabular}{|lll|lllll|}
\hline \hline Drug & $\begin{array}{l}\text { E. coli } \\
(\mathbf{n = 3 5})\end{array}$ & $\begin{array}{l}\text { Klebsiella spp. } \\
(\mathbf{n = 1 4})\end{array}$ & $\begin{array}{l}\text { Proteus } \\
\text { spp. }(\mathbf{n = 9})\end{array}$ & $\begin{array}{l}\text { P. aeruginosa } \\
(\mathbf{n = 9})\end{array}$ & $\begin{array}{l}\text { S. aureus } \\
(\mathbf{n = 1 7})\end{array}$ & $\begin{array}{l}\text { S. saprophyticus } \\
(\mathbf{n = 9})\end{array}$ & $\begin{array}{l}\text { Enterococcus } \\
\text { spp. }(\mathbf{n = 5})\end{array}$ \\
\hline NITRO & $32(91.4)$ & $12(85.7)$ & 0 & $8(89.9)$ & $15(88.2)$ & $9(100.0)$ & $4(80.0)$ \\
\hline NORF & $33(94.3)$ & $9(64.3)$ & 0 & $8(88.9)$ & 0 & 0 & $5(100.0)$ \\
\hline CEFU & $18(51.4)$ & $3(21.4)$ & $8(88.9)$ & $8(88.9)$ & $15(88.2)$ & $8(88.9)$ & $5(100.0)$ \\
\hline AMPI & 0 & 0 & 0 & 0 & 0 & 0 & 0 \\
\hline AMOX- CLAV & 0 & $5(35.7)$ & $8(88.9)$ & 0 & 0 & 0 & 0 \\
\hline IMIPEN & $34(97.1)$ & $9(64.3)$ & $1(11.1)$ & $9(100.0)$ & 0 & 0 & $5(100.0)$ \\
\hline CEFT- SULB & 0 & $9(64.3)$ & $8(88.9)$ & $8(88.9)$ & 0 & 0 & $5(100.0)$ \\
\hline CIPRO & 0 & $7(50.0)$ & $1(11.1)$ & $9(100.0)$ & 0 & 0 & $5(100.0)$ \\
\hline PIPER- TAZO & $11(31.4)$ & $14(100.0)$ & $8(88.9)$ & $9(100.0)$ & 0 & 0 & $5(100.0)$ \\
\hline LEVO & $11(31.4)$ & $14(100.0)$ & $2(22.2)$ & $9(100.0)$ & 0 & 0 & $5(100.0)$ \\
\hline COTRI & 0 & $6(42.9)$ & 0 & 0 & $15(88.2)$ & $9(100.0)$ & 0 \\
\hline
\end{tabular}

Table 6: Culture sensitivity of bacteria in asymptomatic patients $(n=56)$.

\begin{tabular}{|llllllll|}
\hline Drug & $\begin{array}{l}\text { E. coli } \\
(\mathbf{n = 1 8})\end{array}$ & $\begin{array}{l}\text { Klebsiella } \\
\text { spp. }(\mathbf{n = 1 0})\end{array}$ & $\begin{array}{l}\text { Proteus } \\
\text { spp. }(\mathbf{n = 6})\end{array}$ & $\begin{array}{l}\text { P. } \\
\text { aeruginosa }(\mathbf{n = 2})\end{array}$ & $\begin{array}{l}\text { S. aureus } \\
(\mathbf{n = 8})\end{array}$ & $\begin{array}{l}\text { S. saprophyticus } \\
(\mathbf{n = 6})\end{array}$ & $\begin{array}{l}\text { Enterococcus } \\
\text { spp. }(\mathbf{n = 6})\end{array}$ \\
\hline NITRO & $18(100.0)$ & $10(100.0)$ & 0 & $1(50.0)$ & $7(87.5)$ & $\begin{array}{l}6 \\
(100.0)\end{array}$ & $6(100.0)$ \\
\hline NORF & $18(100.0)$ & $5(50.0)$ & 0 & $1(50.0)$ & 0 & 0 & $6(100.0)$ \\
\hline CEFU & $5(27.8)$ & $2(20.0)$ & $6(100.0)$ & $1(50.0)$ & $7(87.5)$ & $6(100.0)$ & $6(100.0)$ \\
\hline AMPI & 0 & 0 & 0 & 0 & 0 & 0 & 0 \\
\hline $\begin{array}{l}\text { AMOX- } \\
\text { CLAV }\end{array}$ & 0 & $5(50.0)$ & $6(100.0)$ & 0 & 0 & 0 & 0 \\
\hline IMIPEN & $18(100.0)$ & $5(50.0)$ & 0 & $2(100.0)$ & 0 & 0 & $6(100.0)$ \\
\hline $\begin{array}{l}\text { CEFT- } \\
\text { SULB }\end{array}$ & 0 & $5(50.0)$ & $6(100.0)$ & $2(100.0)$ & 0 & 0 & $6(100.0)$ \\
\hline CIPRO & 0 & $10(100.0)$ & 0 & $2(100.0)$ & 0 & 0 & $6(100.0)$ \\
\hline $\begin{array}{l}\text { PIPER- } \\
\text { TAZO }\end{array}$ & $5(27.8)$ & $10(100.0)$ & $6(100.0)$ & $1(50.0)$ & 0 & 0 & $6(100.0)$ \\
\hline LEVO & $5(27.8)$ & $10(100.0)$ & 0 & $2(100.0)$ & 0 & 0 & $6(100.0)$ \\
\hline COTRI & 0 & $5(50.0)$ & 0 & 0 & $7(87.5)$ & $6(100.0)$ & 0 \\
\hline
\end{tabular}


Table 5 and Table 6 shows sensitivity pattern of organisms in symptomatic and asymptomatic participants.

\section{Nitrofurantoin (NITRO)}

Majority of the participants in both groups showed overall good sensitivity against the isolated organisms except $P$. aeruginosa in asymptomatic patients which showed sensitivity in only $50 \%$.

\section{Norfloxacin (NORF)}

Majority of the participants in both groups showed overall good sensitivity against the isolated organisms except $P$. aeruginosa and Klebsiella pneumoniae in asymptomatic patients which showed sensitivity in only $50 \%$ women.

\section{Cefuroxime (CEFU)}

Majority of the participants in both the groups showed overall good sensitivity against the isolated organisms except E. coli $(51.4 \%$ and $27.8 \%$ from symptomatic and asymptomatic groups respectively), Klebsiella pneumoniae $(21.4 \%$ and $20 \%$ from two groups respectively) and $P$. aeruginosa $(50 \%$ in asymptomatic women).

\section{Ampicillin (AMPI)}

None of the patient in both groups had any organisms sensitive to ampicillin.

\section{Amoxycillin-clavulanic acid (AMOX-CLAV)}

Only Proteus spp. (88.9\% and $100 \%$ in symptomatic and asymptomatic groups respectively) and Klebsiella pneumoniae $(35.7 \%$ and $50 \%$ women from two groups respectively) were sensitive to amoxicillin-clavulanic acid. Rest of the organisms in both the groups were resistant to amoxicillin-clavulanic acid.

\section{Ciprofloxacin (CIPRO)}

$100 \%$ sensitivity to ciprofloxacin was seen in pseudomonas and enterococcus in symptomatic patients and to both organisms and Klebsiella pneumoniae in asymptomatic patients. Against Proteus spp. and Klebsiella from symptomatic group, sensitivity was $11.1 \%$ and $50 \%$ only. Other organisms were found to be resistant to ciprofloxacin.

\section{Imipenem (IMIPEN)}

$100 \%$ sensitivity to imipenem was seen to Pseudomonas aeruginosa and Enterococci in both the group. It was also $100 \%$ sensitive in E. coli in asymptomatic and $97.1 \%$ sensitive in symptomatic women.

\section{Ceftriaxone-sulbactam (CEF-SULB)}

The sensitivity in two groups was $100 \%$ against Enterococci and against $K$. pneumoniae, Proteus spp. $P$. aeruginosa was $100 \%$ in asymptomatic women and $64.3 \%, 88.9 \%$ and $88.9 \%$ respectively in symptomatic women.

\section{Piperacillin-tazobactam (PIPER-TAZO)}

K. pneumonia, P. aeruginosa and Enterococci in symptomatic women and in addition to the three organisms, Proteus spp. in asymptomatic women showed $100 \%$ sensitivity. Sensitivity of $E$. coli was lower in both groups $(31.4 \%$ and $27.8 \%)$.

\section{Levofloxacin (LEVO)}

$100 \%$ sensitivity was seen in $K$. pneumoniae, $P$. aeruginosa and Enterococci in both groups. Sensitivity of E. coli was lower in both groups (31.4\% and 27.8\%).

\section{Cotrimoxazole (COTRI)}

S. saprophyticus in both groups showed $100 \%$ sensitivity whereas $88.2 \%$ and $87.5 \%$ sensitivity was noted against $S$. aureus in two groups.

\section{DISCUSSION}

Out of total 625 women $17 \%$ patients were symptomatic having one or more symptoms indicative of UTI and $83 \%$ were asymptomatic. Kant et al observed $33.2 \%$ pregnant women to be symptomatic and remaining were asymptomatic. $^{3}$ Assessing symptoms is essential as symptoms assist in reaching the diagnosis in patients with or without UTI.

Table 7: Frequency of UTI in different studies.

\begin{tabular}{|c|c|c|c|}
\hline Frequency of UTI & Symptomatic women & As asymptomatic women & Overall in total women \\
\hline Present study & $92.45 \%$ & $10.7 \%$ & $24.6 \%$ \\
\hline Kant et $\mathbf{a l}^{3}$ & $6.7 \%$ & $1.7 \%$ & $3.3 \%$ \\
\hline Bandyopadhyay et al $^{12}$ & $19.87 \%$ & $4.34 \%$ & - \\
\hline Jain et al $^{13}$ & - & $16.9 \%$ & $16.9 \%$ \\
\hline Mukherjee et al $^{14}$ & - & $8.4 \%$ & $8.4 \%$ \\
\hline Patnaik et al ${ }^{15}$ & - & $25.3 \%$ & $25.3 \%$ \\
\hline
\end{tabular}


We observed dysuria $(74.5 \%)$ was most frequent symptom followed by burning micturition $(54.7 \%)$, pain in abdomen (40.6\%), frequent urination (35.8\%), urgency (33\%), back ache (33\%), fever (27.4\%), flank pain $(25.5 \%)$ and suprapubic pain $(14.2 \%)$ as symptoms reported by patients from symptomatic UTI group. Anozie et al reported frequent urination (27\%), followed by dysuria (25.2\%), nausea-vomiting (18\%), fever $(10.8 \%)$, and suprapubic pain $(8.1 \%)$ as presenting symptoms of UTI. ${ }^{11}$ In presence of such symptoms, patients should be assessed for UTI by culture of the urine which will identify patients early and appropriate treatment can be instituted to prevent any complications (Table 7).

Table 8: Type of organisms isolated in urine culture.

\begin{tabular}{|c|c|c|c|c|c|}
\hline \multirow{2}{*}{$\begin{array}{l}\text { Type of } \\
\text { organism }\end{array}$} & \multicolumn{2}{|l|}{ Our study } & \multirow[t]{2}{*}{ Rizvi et al ${ }^{16}$} & \multirow[t]{2}{*}{ Anozie et al ${ }^{11}$} & \multirow[t]{2}{*}{ Patnaik et al $^{15}$} \\
\hline & Symptomatic & Asymptomatic & & & \\
\hline E. coli & 35.7 & 32.1 & $41.9 \%$ & $62.2 \%$ & $23.52 \%$ \\
\hline K. pnemoniae & 14.3 & 17.9 & $21.7 \%$ & $11.7 \%$ & $45 \%$ \\
\hline Proteus spp. & 9.2 & 10.7 & $6.29 \%$ & $5.4 \%$ & - \\
\hline P. aeruginosa & 9.2 & 3.6 & $3.4 \%$ & $2.7 \%$ & $3.92 \%$ \\
\hline S. aureus & 17.3 & 14.3 & $5.9 \%$ & $13.5 \%$ & $13.72 \%$ \\
\hline S. saprophyticus & 9.2 & 10.7 & $6.4 \%$ & - & - \\
\hline Enterococcus spp. & 5.1 & 10.7 & $3.4 \%$ & - & $9.80 \%$ \\
\hline
\end{tabular}

Table 7 shows frequency of UTI was found to be $24.6 \%$ in our study. Among symptomatic patients, $92.45 \%$ women showed culture positivity whereas $7.5 \%$ women showed no growth on culture. This is much higher prevalence in symptomatic compared to finding of $6.7 \%$ prevalence of UTI reported by Kant et al in symptomatic patients. They further observed the significant association between symptoms and presence of UTI. ${ }^{10}$ Bandyopadhyay et al reported UTI prevalence of $19.87 \%$ in symptomatic women and $4.34 \%$ in asymptomatic women. ${ }^{12}$ This indicates that in ANC women who present with symptoms indicative of urinary tract infection should promptly be evaluated for presence of UTI with laboratory cultures. We observed that frequency of UTI in asymptomatic patients in our study was $10.7 \%$. Jain et al reported prevalence of $16.9 \%$ in their study in women from Northern India. ${ }^{13}$ A study from Mukherjee et al reported prevalence of asymptomatic bacteriuria as $8.4 \% .{ }^{11,14}$ A study from Patnaik et al reported prevalence rate of $25.3 \%$ in women from Eastern India. ${ }^{15}$ Kant et al reported the same in $1.7 \%$ ANC patients. ${ }^{10}$ Thus rates of asymptomatic UTI vary in different parts of India. Such variations in reported prevalences are probably differences in geographical locations, social habits of the communities, socio-economic differences and differences in personal hygiene. It can be concluded from this discussion that UTI prevalence varies widely (Table 8).

In symptomatic women Escherichia coli (35.7\%) was most frequently isolated pathogen followed by $S$. aureus (17.3\%), Klebsiella spp. $(14.3 \%)$, S. saprophyticus, P. aeruginosa, Proteus spp. (9.2\% each) and Enterococcus spp. and $P$. aeruginosa in $7.1 \%$ each.

In asymptomatic women Escherichia coli (32.1\%) was most frequently isolated pathogen followed by Klebsiella spp. (17.9\%), S. aureus (14.3\%), S. saprophyticus,
Proteus spp. and Enterococcus $(10.7 \%$ each) and $P$. aeruginosa in $3.6 \%$.

Rizvi et al reported E. coli $(41.9 \%)$ as most common bacteria followed by Klebsiella pneumoniae $(21.7 \%)$, Citrobacter spp. (7.34\%), Proteus spp. (6.29\%) S. saprophyticus and $S$. epidermidis (6.4\%), S. aureus (5.9\%), Pseudomonas aeruginosa and Enterococcus spp. in $3.4 \%$ each. ${ }^{16}$ Anozie et al observed E. coli in $62.2 \%$ cases followed by $S$. aureus in $13.5 \%, K$. pneumoniae in $11.7 \%$, Proteus mirabilis in $5.4 \%$, and Pseudomonas in $2.7 \%$ cases.

\section{Antibiotic sensitivity pattern of pathogens in symptomatic patients}

Majority of $E$. coli isolates were found to be sensitive to nitrofurantoin, norfloxacin imipenem which are commonly used antibiotics in pregnancy. Lower rate of sensitivity was found with cefuroxime in Klebsiella spp. $(21.4 \%)$ and ciprofloxacin in Proteus spp. (11.1\%). Enterococci were $100 \%$ sensitive to most antibiotics including norfloxacin and $80 \%$ sensitive to nitrofurantoin. None of the isolated pathogen were sensitive to ampicillin. Patnaik et al reported $100 \%$ sensitivity of Escherichia coli isolates to Cefepime, Nitrofurantoin and Cotrimoxazole. ${ }^{15}$

Sensitivity of Klebsiella spp. to different antibiotics was found as: cefepime (95.65\%), gentamicin (78.26\%), nitrofurantoin $(78.26 \%)$, norfloxacin $(60.86 \%)$, cefixime $(52.17 \%)$, cefpodoxime $(47.82 \%)$, cefuroxime $(47.82 \%)$ and cotrimoxazole (43.47\%), amoxiclav (39.13\%). All the gram-positive isolates were $100 \%$ sensitive to nitrofurantoin, cotrimoxazole, linezolid and vancomycin. Rizwi et al reported $100 \%$ sensitivity of Enterobacteriaceae and Pseudomonas spp. to imipenem 
and $60 \%$ to nitrofurantoin. ${ }^{16}$ In $S$. aureus and $S$. saprophyticus, highest sensitivity was reported for oxacillin $(65.9 \%$ and $66 \%)$.

\section{Antibiotic sensitivity pattern of pathogens in asymptomatic cases}

Most isolates identified on culture were sensitive to nitrofurantoin, norfloxacin and imipenem suggesting these should be the antibiotic of choice. No isolates were found sensitive to ampicillin. Mukherjee et al reported $66.67 \%$ sensitivity of $E$. coli and $K$. pneumoniae to nitrofurantoin. S. aureus showed $100 \%$ sensitivity to ciprofloxacin, cefotaxime, and ceftriaxone. Patnaik et al reported $100 \%$ sensitivity of Escherichia coli isolates to Cefepime, Nitrofurantoin and Cotrimoxazole. ${ }^{15}$

WHO recommends a 7-day course of antibiotics in asymptomatic bacteriuria patients to prevent the complications. $^{9}$ ACOG guidelines suggest if no options are available, nitrofurantoin can be used in first trimester. $^{17}$

\section{CONCLUSION}

In this study of 625 antenatal women attending the OPD, frequency of urinary tract infection was 154 ( 24.6\%). Out of 625 antenatal women $17 \%$ women were symptomatic having one or more symptoms indicative of UTI and $83 \%$ were asymptomatic. Among symptomatic women, $92.45 \%$ women showed culture positivity for one or more bacteria whereas in asymptomatic women, culture was positive in $10.7 \%$. E c coli followed by Klebsiella were the most common isolate identified in both symptomatic and asymptomatic pregnant women. On antibiotic sensitivity testing, we found good overall sensitivity of bacteria to commonly used antibiotics such as nitrofurantoin, and norfloxacin but resistant to ampicillin was observed in all women. UTI adversely affects the mother like pyelonephritis, preterm labour, premature baby and its complications.

So it is important to identify presence of UTI during pregnancy by doing urine routine and culture sensitivity test in all antenatal women and administration of appropriate antibiotic to affected women so as to reduce the development of morbidity both in mother and baby.

\section{ACKNOWLEDGMENTS}

Authors are thankful to Dr. S. Joshi, Head of the Department of Obstetrics and Gynecology NKP Salve Institute of Medical Sciences, Nagpur (MS) for her valuable guidance and support.

Funding: No funding sources Conflict of interest: None declared

Ethical approval: The study was approved by the Institutional Ethics Committee

\section{REFERENCES}

1. Totsika M, Gomes Moriel D, Idris A, Rogers AB, Wurpel JD, Phan M. Uropathogenic Escherichia coli mediated urinary tract infection. Current Drug Targets. 2012;13:1386-99.

2. Medina M, Castillo-Pino E. An introduction to the epidemiology and burden of urinary tract infections. Therap Adv Urol. 2019;11:3-7.

3. Kant S, Lohiya A, Kapil A, Gupta SK. Urinary tract infection among pregnant women at a secondary level hospital in Northern India. Indian $\mathbf{J}$ Public Health. 2017;61:118.

4. Delzell J, Lefevre M. Urinary tract infections during pregnancy. Am Fam Phys. 2000;61:713-20.

5. Manjula NG, Math GC, Patil A, Gaddad SM, Shivannavar CT. Incidence of urinary tract infections and its aetiological agents among pregnant women in Karnataka region. Adv Microbiol. 2013;3:473.

6. WHO Reproductive Health Library. WHO recommendation on the method for diagnosing asymptomatic bacteriuria in pregnancy (December 2016). The WHO Reproductive Health Library; Geneva: World Health Organization. Available from: https://extranet.who.int/. Accessed on 15 December 2019.

7. Antenatal care. National Collaborating Centre for Women's and Children's Health (NICE) Clinical Guideline. 2008. www.rcog.org.uk. Accessed on 22 December 2019.

8. Smaill F. Antibiotics for asymptomatic bacteriuria in pregnancy. Cochrane Database Sys Rev.2000;(2).

9. Nguefack CT, Ebongue CO, Chokotheu CN, Ewougo CE, Njamen TN, Mboudou E. Clinical presentation, risk factors and pathogens involved in bacteriuria of pregnant women attending antenatal clinic of 3 hospitals in a developing country: a cross sectional analytic study. BMC Pregnanc Childbirth. 2019; 19:143.

10. Asymptomatic Bacteriuria in Adults: Screening. US Preventive Task Force. 2008. Available from: www.uspreventiveservicestaskforce.org. Accessed on 22 December 2019.

11. Anozie OB, Lawani OL, Esike CU, Mamah E, Ajah LO. Prevalence and common microbial isolates of urinary tract infection in pregnancy; a four year review in a tertiary health institution in Abakaliki, south-east Nigeria. Am J Clin Med Res. 2016;4:25-8.

12. Bandyopadhyay S, Thakur JS, Ray P, Kumar R. High prevalence of bacteriuria in pregnancy and its screening methods in north India. J Indian Med Assoc. 2005;103:259-62.

13. Jain V, Das V, Agarwal A, Pandey A. Asymptomatic bacteriuria and obstetric outcome following treatment in early versus late pregnancy in north Indian women. Indian J Med Res. 2013;137:753.

14. Mukherjee K, Golia S, Vasudha CL, Babita BD, Chakroborti G. A study on asymptomatic bacteriuria in pregnancy: prevalence, etiology and comparison 
of screening methods. Int $\mathrm{J}$ Res Med Sci. 2014;2:1085-91.

15. Patnaik M, Panigrahi K, Das B, Pathi B, Poddar N, Lenka PR, et al. Prevalence, risk factors and causative organisms of asymptomatic bacteriuria in pregnancy. Int J Adv Med. 2017;4:1348-54.

16. Rizvi M, Khan F, Shukla I, Malik A. Rising prevalence of antimicrobial resistance in urinary tract infections during pregnancy: necessity for exploring newer treatment options. J Lab Phys. 2011;3:98.

17. Sulfonamides, Nitrofurantoin, and Risk of Birth Defects. The American College of Obstetrics and
Gynaecology (ACOG) Committee Opinion, 2017. Available from; https://www.acog.org/clinical/ clinical-guidance/committee-opinion/articles /2017/09/sulfonamides-nitrofurantoin-and-risk-ofbirth-defects. Accessed on 22 December 2019.

Cite this article as: Sadhvi K, Kose V. Frequency of urinary tract infections among pregnant women receiving antenatal care in a tertiary care centre: hospital based cross-sectional study. Int J Reprod Contracept Obstet Gynecol 2021;10:207-14. 